\title{
A New Look at Familial Risk of Inflammatory Bowel Disease in the Ashkenazi Jewish Population
}

\author{
Elena R. Schiff ${ }^{1}$ - Matthew Frampton ${ }^{1} \cdot$ Francesca Semplici $^{1}$ - Stuart L. Bloom ${ }^{2}$ - Sara A. McCartney ${ }^{2} \cdot$ Roser Vega $^{2}$. \\ Laurence B. Lovat $^{2,3} \cdot$ Eleanor Wood $^{4} \cdot$ Ailsa L. Hart $^{5} \cdot$ Daniel Crespi $^{6} \cdot$ Mark A. Furman $^{6} \cdot$ Steven Mann $^{7}$. \\ Charles D. Murray ${ }^{8} \cdot$ Anthony W. Segal $^{1}$. Adam P. Levine ${ }^{1}$
}

Received: 4 May 2018 / Accepted: 18 July 2018 / Published online: 3 September 2018

(c) The Author(s) 2018

\begin{abstract}
Background and Aims The inflammatory bowel diseases (IBD) are particularly common among the Ashkenazi Jewish (AJ) population. Population-specific estimates of familial risk are important for counseling; however, relatively small cohorts of AJ IBD patients have been analyzed for familial risk to date. This study aimed to recruit a new cohort of AJ IBD patients, mainly from the UK, to determine the familial occurrence of disease.

Methods A total of 864 AJ IBD patients were recruited through advertisements, hospital clinics, and primary care. Participants were interviewed about their Jewish ancestry, disease phenotype, age of diagnosis, and family history of disease. Case notes were reviewed.

Results The 864 probands comprised 506 sporadic and 358 familial cases, the latter with a total of 625 affected relatives. Of the UK cases, $40 \%$ had a positive family history with $25 \%$ having at least one affected first-degree relative. These percentages were lower among those recruited through hospital clinics and primary care (33\% for all relatives and $22 \%$ among first-degree relatives). Examining all probands, the relative risk of IBD for offspring, siblings, and parents was 10.5, 7.4, and 4, respectively. Age of diagnosis was significantly lower in familial versus sporadic patients with Crohn's disease.

Conclusions This study reports familial risk estimates for a significant proportion of the AJ IBD population in the UK. The high rate of a positive family history in this cohort may reflect the greater genetic burden for IBD among AJs. These data are of value in predicting the likelihood of future recurrence of IBD in AJ families.
\end{abstract}

Keywords Epidemiology $\cdot$ Inflammatory bowel disease $\cdot$ Familial risk $\cdot$ Ashkenazi Jewish

\section{Abbreviations}

AJ Ashkenazi Jewish

FDR First-degree relative

\section{Introduction}

Crohn's disease (CD) and ulcerative colitis (UC) are the two major forms of inflammatory bowel disease (IBD), a heterogeneous group of chronic and debilitating disorders characterized by inflammation of the gastrointestinal tract $[1$, 2]. IBD is a global disease, the prevalence and incidence of which have significantly increased since the 1950 s, particularly over the last few decades in developed countries [3].

Elena R. Schiff

e.schiff@ucl.ac.uk

Extended author information available on the last page of the article
Recent estimates suggest that the prevalence of IBD is over $0.3 \%$ in North America, Australia, and many countries in Western Europe. IBD is also emerging in newly industrialized countries as they adopt a Westernized diet and lifestyle [4].

The etiology of IBD is thought to involve an aberrant immune response to commensal microflora in genetically susceptible individuals exposed to environmental risk factors [5, 6]. Epidemiological studies have consistently shown an increased prevalence of IBD among first-degree relatives (FDRs) of patients with CD and UC; this familial clustering, in addition to the increased incidence of disease among monozygotic (MZ) twins, provided the initial evidence of a genetic predisposition to IBD $[7,8]$. Concordance in MZ twins is $>30 \%$ for $\mathrm{CD}$ and $16 \%$ for UC, while only $4 \%$ for both in dizygotic twins $[9,10]$. A positive family history is the strongest risk factor for developing IBD; FDRs of an IBD patient have a $10-15$ times greater risk of the disease 
compared with the general population [11, 12]. If both parents have IBD, the lifetime risk to their offspring is thought to be over $30 \%[13,14]$.

The Jewish population comprises three main groups: Ashkenazim, Sephardim, and Mizrahim. The Ashkenazi Jewish (AJ) population is a founder population that comprises the majority of contemporary world Jewry. From the twelfth century, AJs lived in Central and Eastern Europe, moving primarily to the USA, Western Europe, and Israel in the late nineteenth and early to mid-twentieth centuries [15]. The AJ population was subjected to repeated bottlenecks and has maintained its genetic isolation through endogamy, practiced for religious and cultural reasons. This genetic isolation is evidenced by the high prevalence of founder mutations [16] corresponding to over 100 autosomal recessive disorders [17] as well as a high frequency of risk variants for common diseases such as breast and ovarian cancer, Parkinson's disease, and IBD [18].

IBD is particularly common among the AJ population as demonstrated in epidemiological studies in disparate geographic locations since the 1960s [19-26]. The latest published data suggest an approximately fourfold increased risk of IBD among AJs [27]. There are no recent published epidemiological studies assessing the prevalence of IBD in the contemporary AJ population. Using an IBD prevalence of $0.3 \%$ [4], a fourfold increase among AJs yields an estimated prevalence of $1.2 \%$. Previous studies reporting familial empirical risk estimates for IBD in the AJ population have been undertaken over 25 years ago using modest cohort sizes $[26,28]$.

The AJ population in the $\mathrm{UK}$ is thought to represent about $95 \%$ of the total UK Jewish population, which an analysis of the 2011 national census enumerated as 271,259 individuals [29]. The contemporary UK Jewish population is estimated to display a relatively high degree of endogamy at $74 \%$ [30]. Using an AJ IBD prevalence of $1.2 \%$, there are an estimated 3100 AJ IBD cases in the UK.

The aim of this study was to recruit a new cohort of AJ IBD patients and their families, primarily from the UK, for epidemiological and genetic investigations [31]. Using 864 AJ IBD-affected individuals, up-to-date estimates of the pattern of familial disease and the risk to relatives are provided. Such data are relevant for genetic counseling.

\section{Methods}

\section{Ethics}

Ethical and research governance approval was provided by The National Research Ethics Service London Surrey Borders Committee (10/H0906/115) and the University College
London Research Ethics Committee (6054/001). Informed consent was obtained from all participants.

\section{Recruitment}

Individuals with IBD were recruited through advertisements in Jewish press, predominantly in the UK but also in Israel and the USA, and via referrals from specialist IBD clinics and primary care (UK only). Recruitment was undertaken from 2013 to 2017. Participants were interviewed by telephone to ascertain their Jewish ancestry, IBD phenotype, age of diagnosis, and family history of IBD in both FDRs and distant relatives. Only individuals of self-reported AJ ancestry were included; those with Sephardi, Mizrahi, or mixed ancestry were excluded. IBD cases were considered to have "sporadic" IBD if there were no known relatives with the disease. They were considered to have "familial" disease if a first, second, or more distant relative was reported to have a diagnosis of CD or UC. The diagnosis of IBD in probands (index cases) and their relatives was evaluated by asking them detailed questions about their diagnosis, clinical course, and treatment. Through the probands, the majority $(66 \%)$ of their affected relatives were subsequently recruited from the UK and multiple countries worldwide including Australia, Belgium, Canada, France, Gibraltar, Israel, Netherlands, Norway, Portugal, South Africa, Switzerland, and the USA. Where possible a written confirmation of each affected individual's diagnosis was obtained from his or her doctor. Sporadic and familial IBD cases were compared for IBD phenotype and age of diagnosis. Familial risk estimates were calculated. The ages of diagnosis in parent-offspring pairs was examined. Saliva samples were collected for genetic investigations.

\section{Statistics}

$2 \times 2$ comparisons were made using Fisher's exact test (twotailed). Multi-group comparisons for continuously distributed data were made using Tukey's honest significant difference test. Single-group comparisons for continuously distributed data were made using Wilcoxon signed-rank test. Data analysis was performed in R.

\section{Results}

\section{Participants}

A total of 864 AJ index cases with IBD were recruited. Of these, 506 individuals had no family history of IBD (sporadic) and 358 reported one or more affected relative(s) (familial). In the families, there were a total of 625 additional affected relatives (301 FDRs and 324 more distant 
Table 1 Family history of IBD in all relatives and in first-degree relatives (FDRs) only of IBD probands, according to the method of recruitment

\begin{tabular}{lcrr}
\hline Recruitment method & IBD probands & \multicolumn{2}{c}{ Positive family history } \\
\cline { 3 - 4 } & & \multicolumn{1}{c}{ All } & FDRs only \\
\hline Advertisements (UK) & 529 & $231(44 \%)$ & $144(27 \%)$ \\
Hospitals, primary care & 276 & $91(33 \%)$ & $61(22 \%)$ \\
$\quad(U K)$ & & & \\
Total (UK) & 805 & $322(40 \%)$ & $205(25 \%)$ \\
International & 59 & $36(61 \%)$ & $26(44 \%)$ \\
Total (overall) & 864 & $358(41 \%)$ & $231(27 \%)$ \\
\hline
\end{tabular}

relatives); information was directly obtained from 411 of these. Of the total 1489 AJ IBD individuals in the cohort, $1261(85 \%)$ were currently resident in the UK. Assuming a $1.2 \%$ prevalence of IBD in AJs, the cohort represents over $40 \%$ of the total predicted UK AJ IBD population.

\section{Distribution of Disease and Family History}

The percentage of probands with a positive family history of IBD in any relative was $41 \%$ (Table 1 ). The number of probands with a FDR with IBD was 231 (27\%). The percentage of probands in the UK with a positive family history in any relative was significantly greater when the proband was recruited through advertising (44\%) than through hospital clinics and primary care (33\%) (Fisher's exact test $p=0.004)$ but not in FDRs only $(p=0.13)$. The percentage of probands with a positive family history in any relative and among FDRs only was significantly greater among probands recruited internationally $(p=0.002$ and $p=0.003$, respectively).

Table 2 shows the distribution of all 1489 affected individuals by type of IBD in familial and sporadic cases; a greater number of affected individuals had CD than UC in both the familial and sporadic groups. Of the 864 probands, 528 (61\%) had CD and 319 (37\%) had UC. The remaining 17 (2\%) had either a clinically indeterminate phenotype (IBD unclassified) or their subtype was unknown.

A greater proportion of $\mathrm{CD}$ probands had an affected FDR (27\%) than of UC probands (20\%), $p=0.03$. There was no significant difference in any positive family history among those with $\mathrm{CD}(43 \%)$ versus UC $(41 \%), p=0.62$.

While affected relatives of a proband may develop either form of IBD, the greatest risk to a relative was for the concordant type, particularly for a CD proband (examining FDRs: $83 \%$ for $\mathrm{CD}$ versus $62 \%$ for $\mathrm{UC}, p=0.0007$ ). Table 3 shows the distribution of concordant and discordant FDRs of these probands.

The distribution of the total number of ascertained familial affected individuals in each of the 358 multiplex
Table 2 Distribution of familial and sporadic patients by inflammatory bowel disease subtype in probands and the entire cohort

\begin{tabular}{lll}
\hline & Probands only $(\%)$ & All $(\%)$ \\
\hline All IBD & & \\
CD & $528(61 \%)$ & $885(59 \%)$ \\
UC & $319(37 \%)$ & $532(36 \%)$ \\
IBDU & $17(2 \%)$ & $72(4 \%)$ \\
Total & 864 & 1489 \\
Familial IBD & & \\
CD & $225(63 \%)$ & $582(59 \%)$ \\
UC & $130(36 \%)$ & $343(35 \%)$ \\
IBDU & $3(1 \%)$ & $58(6 \%)$ \\
Total & 358 & 983 \\
Sporadic IBD & & \\
CD & $303(60 \%)$ & \\
UC & $189(37 \%)$ & \\
IBDU & $14(3 \%)$ & \\
Total & 506 &
\end{tabular}

$C D$ Crohn's disease, $U C$ ulcerative colitis, $I B D U$ inflammatory bowel disease unclassified/unknown

Table 3 Distribution of all concordant and discordant affected FDRs of $209 \mathrm{CD}$ and UC probands

\begin{tabular}{lllll}
\hline $\begin{array}{l}\text { Number of familial } \\
\text { probands with } \geq 1 \\
\text { affected FDR by phe- } \\
\text { notype }\end{array}$ & $\begin{array}{l}\text { Total number of affected FDRs by phe- } \\
\text { notype }\end{array}$ & CD & UC & Total \\
\hline CD & 144 & $161(83 \%)$ & $34(17 \%)$ & 195 \\
UC & 65 & $29(38 \%)$ & $48(62 \%)$ & 77 \\
Total & 209 & 190 & 82 & 272 \\
\hline
\end{tabular}

Concordant phenotypes are indicated by italics

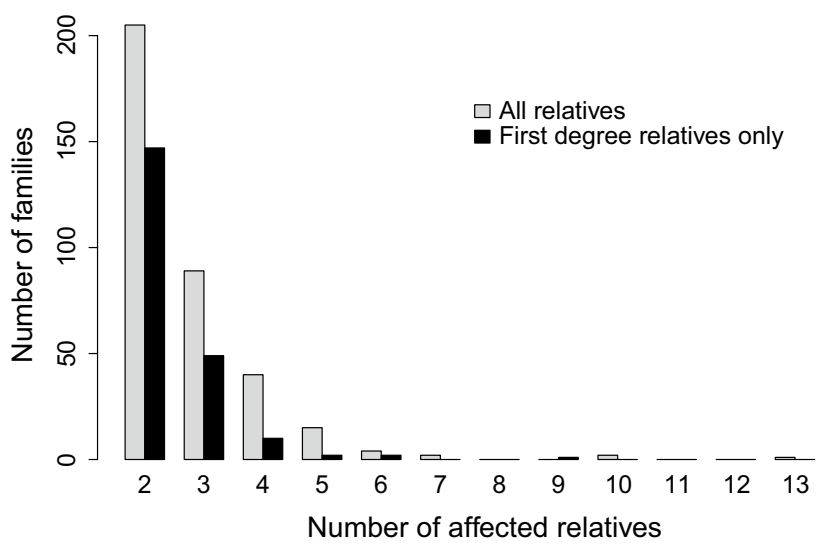

Fig. 1 Distribution of the number of ascertained families by number of affected relatives (all and first-degree relatives only separately) 
families is shown in Fig. 1, separately for all affected relatives and for affected FDRs only. There were 24 families with five or more affected individuals. There were $146 \mathrm{CD}$ or UC probands with affected relatives none of whom were FDRs. In at least 10 families, the disease was present in two or more unrelated branches of the family.

\section{IBD in Spouses}

Eight probands had an affected spouse; five of the couples (62.5\%) were concordant for IBD phenotype: four for CD and one for UC. The mean age of disease diagnosis was 23.9 in the first affected spouse and 24.8 in the second affected spouse. Only one of the 25 offspring of these eight couples was affected (diagnosed at 15 years of age); however, 18 of the remaining 24 offspring were under 20 years old at the time of ascertainment, and some of them may yet manifest IBD.

\section{Relative Risks in FDRs}

Details of the number and affected status of all FDRs were provided by the majority of the 864 probands. In order to prevent an overestimation of the relative risk due to a potential biased inclusion of affected versus unaffected relatives, probands were excluded when the number and phenotype of all FDRs were incomplete. For two probands, there was no information regarding the parents. The frequency with which probands were excluded due to incomplete FDR information was greater in sporadic versus familial cases for both offspring and siblings (30.8\% vs. $11.2 \%$ and $36.2 \%$ vs. $9.2 \%$, respectively). Six hundred and sixty-eight probands had 738 offspring, of whom 93 (13\%) were affected. Using the estimated prevalence of IBD in the AJ population of $1.2 \%$ (as above), the relative risk for offspring was 10.5 . The relative risks for sibling and parents were 7.4 and 4, respectively. The likelihood of having a child with IBD was slightly greater if the proband had CD than if they had UC (14\% vs. $9 \%$ for offspring), although not quite reaching statistical significance $(p=0.06)$. Table 4 summarizes these data, showing the percentage of offspring, siblings, and parents affected and the respective relative risks, for all IBD, for $\mathrm{CD}$, and for UC probands. Relative risks or percentages of affected FDRs from other studies are provided for comparison. Examining only familial cases for IBD, the relative risks for offspring, siblings, and parents were 17.0, 12.9, and 9.7, respectively (data not shown).

\section{Age of Diagnosis of IBD in Cases}

The age of diagnosis differed significantly between $\mathrm{CD}$ and UC and familial and sporadic cases, as shown in Fig. 2. The data demonstrated a positive skew. The lowest age of diagnosis was observed in CD familial cases (median 20 years), and the greatest age of diagnosis was observed in UC sporadic cases (median 28.5 years). CD familial cases were statistically significantly younger at diagnosis than CD sporadic cases $\left(p=1.4 \times 10^{-5}\right)$ and UC familial cases $\left(p=2.5 \times 10^{-6}\right)$. The age at diagnosis of sporadic CD and UC cases, and UC familial and sporadic cases was not statistically different.

\section{Parent and Offspring Ages of Diagnosis}

Of the 124 parent-offspring duos from whom ages of diagnosis were available, $79 \%$ of the children were diagnosed at a younger age than the affected parent, with a median age difference of 13 years $\left(p=3 \times 10^{-14}\right)$. This reduced to eight years but remained statistically significant $\left(p=1 \times 10^{-6}\right)$ when only parents diagnosed aged $\leq 40$ years at the time of analysis were considered, in order to prevent an inadequate follow-up time bias of the offspring compared to the parents $[32,33]$.

\section{Discussion}

This study reports updated familial risk estimates for the AJ IBD population utilizing a large newly recruited cohort, predominantly from the UK. Assuming a 1.2\% prevalence of IBD in AJs, the 1261 AJ IBD individuals from the UK in this cohort represent a significant proportion (over 40\%) of the estimated total UK AJ IBD population. The resulting risk estimates may be of benefit for genetic counseling. We report a $40 \%$ familial incidence of IBD in the UK with $25.5 \%$ of individuals with IBD having at least one first-degree relative with IBD. This is somewhat high in comparison with previous studies in non-AJ populations and is partly driven by the high number of familial cases who responded to our advertisements. Limiting the familial incidence estimates to cases recruited through hospitals and clinics (unbiased to family history status), we report a 33\% familial incidence of IBD with $22.1 \%$ of individuals having at least one affected FDR. This matches well with results from a large recent study in the USA of 2136 patients with IBD (of variable ethnicity) which reported $32 \%$ familial incidence of IBD with $17 \%$ having at least one affected first-degree relative [34]. In a review of studies published up to 2002 [12], the occurrence of a positive family history of IBD varied from 5 to $16 \%$ in $\mathrm{CD}$ and 8 to $14 \%$ in UC. Large multigenerational studies from Sweden and Holland reported first-degree familial incidence of IBD in 6-12\% [35, 36].

The rate of familial IBD observed in our cohort is greater than that of previous studies examining the AJ population (Table 5). However, it is important to note that there are challenges when comparing different studies 
Table 4 Calculation of relative risk of IBD in first-degree relatives (FDRs) of patients with IBD, CD and UC

\begin{tabular}{|c|c|c|c|}
\hline & \multicolumn{3}{|c|}{ Relative type } \\
\hline & Offspring & Siblings & Parents \\
\hline \multicolumn{4}{|c|}{ All probands ( $n=864 ; 506$ sporadic, 358 familial) } \\
\hline Total affected and unaffected, $t$ & $738(668)$ & $1407(648)$ & $1724(862)$ \\
\hline Number affected, $m$ & $93(318)$ & $125(325)$ & $83(356)$ \\
\hline Unaffected FDRs of sporadic probands & $281(350)$ & $600(323)$ & $1012(506)$ \\
\hline Unaffected FDRs of familial probands & $364(318)$ & $682(325)$ & $629(356)$ \\
\hline Percentage affected in all families, $f=m / t$ & $13 \%$ & $9 \%$ & $5 \%$ \\
\hline Relative risk in all families, $r=f / p$ & 10.5 & 7.4 & 4 \\
\hline \multicolumn{4}{|c|}{ All CD probands ( $n=528 ; 303$ sporadic, 225 familial) } \\
\hline Total affected and unaffected, $t$ & $478(400)$ & $962(390)$ & $1054(527)$ \\
\hline Number affected, $m$ & $69(196)$ & $90(204)$ & $51(224)$ \\
\hline Percentage affected in all families, $f=m / t$ & $14 \%$ & $9 \%$ & $5 \%$ \\
\hline Relative risk in all families, $r=f / p$ & 12 & 7.8 & 4 \\
\hline \multicolumn{4}{|c|}{ All UC probands ( $n=319 ; 189$ sporadic, 130 familial) } \\
\hline Total affected and unaffected, $t$ & $246(257)$ & $426(248)$ & $636(318)$ \\
\hline Number affected, $m$ & $23(119)$ & $34(118)$ & $31(129)$ \\
\hline Percentage affected in all families, $f=m / t$ & $9 \%$ & $8 \%$ & $5 \%$ \\
\hline Relative risk in all families, $r=f / p$ & 7.8 & 6.7 & 4.1 \\
\hline \multicolumn{4}{|c|}{$\begin{array}{l}\text { Percentages of affected FDRs in other AJ studies } \\
\text { Roth et al. [28] }\end{array}$} \\
\hline Uncorrected prevalence, $n=154$ & $3 \%$ & $5 \%$ & $3 \%$ \\
\hline Age-corrected prevalence, $n=154$ & $9 \%$ & $9 \%$ & $4 \%$ \\
\hline \multicolumn{4}{|l|}{ Yang et al. [26] } \\
\hline Uncorrected prevalence in $\mathrm{CD}, n=134$ & $2 \%$ & $8 \%$ & $3 \%$ \\
\hline Age-corrected prevalence in CD, $n=134$ & $7 \%$ & $17 \%$ & $4 \%$ \\
\hline Uncorrected prevalence in UC, $n=157$ & $2 \%$ & $2 \%$ & $3 \%$ \\
\hline Age-corrected prevalence in UC, $n=157$ & $7 \%$ & $5 \%$ & $4 \%$ \\
\hline \multicolumn{4}{|l|}{ Satsangi et al. [42] } \\
\hline Relative risk of IBD, $n=433$ & 24.7 & 12.5 & 4.4 \\
\hline
\end{tabular}

The number of probands from whom FDR information was available is in brackets. $p$ : assumed prevalence of IBD in AJ population, $1.2 \%$

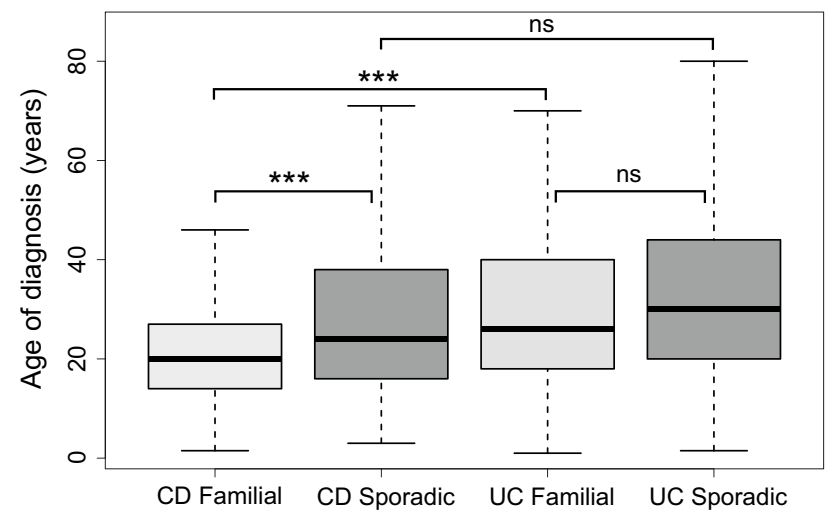

Fig. 2 Box and whisker plots showing the distribution of age of diagnosis in Crohn's disease (CD) and ulcerative colitis (UC) in familial and sporadic cases separately. ${ }^{* * *} p<2 \times 10^{-5}, n s$ nonsignificant given differing study designs and ascertainment methodologies. Defining familial IBD varies with some studies reporting family history in FDRs only and others including more distantly related relatives (e.g., second and third degree), as has been done in the present study. Some studies assign the risk of CD or UC [37-40], while others assign a risk to all types of IBD together [26, 28].

Accurate empirical risk estimates are one of the most important tools for genetic counselors in supporting families and explaining complex diseases such as IBD [41] where the collective effect of multiple genetic loci has not been fully determined. The empirical risk estimates for siblings are more reliable compared to those for offspring or parents because probands and their siblings live temporally, removing generational bias [26]. Parents consistently have the lowest risk estimates, perhaps due to improved diagnosis and consistent with the increasing incidence of 
Table 5 Comparison between the present cohort and previous studies on the occurrence of familial IBD in AJs, showing occurrence of any affected relatives and affected firstdegree relatives in probands with IBD

\begin{tabular}{lllll}
\hline Study & Phenotype & $\begin{array}{l}\text { Number of AJ } \\
\text { probands }\end{array}$ & $\begin{array}{l}\text { Any family } \\
\text { history }\end{array}$ & FDR with IBD \\
\hline Roth et al. [28] & IBD & 154 & $23.4 \%$ & $17.6 \%$ \\
Zlotogora et al. [37] & CD & 157 & NA & $6.6 \%$ \\
Yang et al. [26] & IBD & 291 & $24.3 \%$ & NA \\
Zhou et al. [38] & CD & 481 & $22.8 \%$ & NA \\
Ben-Horin et al. [39] & CD & 181 & NA & $16 \%$ \\
Ben-Horin et al. [39] & UC & 168 & NA & $14 \%$ \\
This study_total & IBD & 864 & $41 \%$ & $25 \%$ \\
This study_UK & IBD & 805 & $40 \%$ & $26 \%$ \\
This study_UK & CD & 484 & $41 \%$ & $28 \%$ \\
This study_UK & UC & 304 & $41 \%$ & $22 \%$ \\
This study_UK Hospitals and & IBD & 276 & $33 \%$ & $22 \%$ \\
primary care only & & & & \\
\hline
\end{tabular}

${ }^{a}$ The studies by Ben-Horin et al. examined the Israeli Jewish population; approximately $40 \%$ of the probands were Ashkenazi
IBD in recent years. The relative risk for parents in our study was consistent with the literature [28, 42].

It has previously been observed that familial IBD cases tend to have an earlier age of onset compared to sporadic cases [34, 38, 43] although not all studies agree [44]. We observed this in our cohort for CD but not UC. Recent studies demonstrate that positive family history is also associated with complicated $\mathrm{CD}$ behavior and the need for IBD-related surgery $[34,45,46]$, indicating the importance of establishing a family history for clinical and treatment prognostication. Information regarding disease severity was not collected in this study.

Our observation of a generational difference in the age of diagnosis in parent-offspring duos is consistent with previous studies in IBD [47-49]. Genetic anticipation as an explanation for this finding has been shown to be unlikely, and it is thought instead that ascertainment biases, especially inadequate follow-up time, are responsible [33, 50, 51].

Limitations of this study include potential biases and inconsistencies introduced in the recruitment process. The majority of affected individuals and their respective families were recruited through advertisements in the Jewish press; the second largest recruitment source was IBD clinics from five London hospitals in areas with a high Jewish population. As teaching hospitals, the latter are more likely to attract patients with severe disease, more common in familial cases [34]. Two potential issues with recruitment by advertisements are worth noting. Firstly, in contrast to the IBD clinics, participants responding to the advertisements self-reported their phenotypes. In the majority of cases $(56 \%)$, the phenotype was independently verified by the patient's clinician but this was not always possible. Self-reported IBD status has previously been found to be highly accurate $[52,53]$. The other issue with recruitment by advertisement relates to the potential bias toward familial IBD. Since the aim of this study was also to identify multiplex families for genetic analysis, the advertisement particularly encouraged participation of such cases. This is evident in the data in which the percentage of probands with a family history was greater among those recruited by advertisement. It is also possible that there was more of an incentive to participate in a genetic study for familial cases.

Furthermore, we have also relied on probands selfreporting a positive or negative family history. The reliability of this has not been previously studied for IBD, although it has been demonstrated to be accurate for some cancers $[54,55]$. Lack of contact with relatives may cause underreporting of IBD in a family, while ignorance of diagnosis may cause over-reporting.

The lifetime risk of IBD in the probands' relatives has not been adjusted for age. Since many of the relatives are young, they may still develop IBD. The relative risks calculated may thus be underestimated, although the aforementioned biases may counteract this.

This study characterizes a newly recruited AJ IBD population and examines the distribution of family history in detail. The relatively high rate of a positive family history in this cohort may reflect the greater genetic burden for IBD among AJs [56, 57]. Such data and the relative risk estimates are of value in predicting the likelihood of future recurrence of IBD in a family.

Acknowledgments The authors kindly acknowledge all study participants, clinical collaborators, and Alex Hall for her help in recruiting.

Funding This work was supported by the Charles Wolfson Charitable Trust and the Medical Research Council. 
Author's contribution ERS designed the study, recruited the participants, collected and analyzed the data, and drafted and revised the manuscript; MF analyzed the data; FS collected the data; SLB, SM, RV, LBL, EW, ALH, DC, MAF, SAM, and CDM recruited the participants; AWS designed and supervised the study; APL designed and supervised the study, analyzed the data, and revised the manuscript.

\section{Compliance with ethical standards}

\section{Conflict of interest None.}

Open Access This article is distributed under the terms of the Creative Commons Attribution 4.0 International License (http://creativeco mmons.org/licenses/by/4.0/), which permits unrestricted use, distribution, and reproduction in any medium, provided you give appropriate credit to the original author(s) and the source, provide a link to the Creative Commons license, and indicate if changes were made.

\section{References}

1. Torres J, Mehandru S, Colombel J-F, Peyrin-Biroulet L. Crohn's disease. Lancet. 2017;389:1741-1755. https://doi.org/10.1016/ S0140-6736(16)31711-1.

2. Ungaro R, Mehandru S, Allen PB, Peyrin-Biroulet L, Colombel J-F. Ulcerative colitis. Lancet. 2017;389:1756-1770. https://doi. org/10.1016/S0140-6736(16)32126-2.

3. Molodecky NA, Soon IS, Rabi DM, et al. Increasing incidence and prevalence of the inflammatory bowel diseases with time, based on systematic review. Gastroenterology. 2012;142:46-54. https://doi.org/10.1053/j.gastro.2011.10.001.

4. Ng SC, Shi HY, Hamidi N, Underwood FE, Tang W, Benchimol EI et al. Articles Worldwide incidence and prevalence of inflammatory bowel disease in the 21 st century: a systematic review of population-based studies 2017. https://doi.org/10.1016/s0140 -6736(17)32448-0.

5. Malik TA. Inflammatory bowel disease. Historical perspective, epidemiology, and risk factors. Surg Clin North Am. 2015. https ://doi.org/10.1016/j.suc.2015.07.006.

6. Segal AW. Making sense of the cause of Crohn's-a new look at an old disease. F1000Research. 2016;5:2510. https://doi. org/10.12688/f1000research.9699.2.

7. Kirsner JB, Spencer JA. Family occurrences of ulcerative colitis, regional enteritis, and ileocolitis. Ann Intern Med. 1963;59:133-144

8. Hislop IG, Grant AK. Genetic tendency in Crohn's disease. Gut. 1969;10:994-995.

9. Brant SR. Update on the heritability of inflammatory bowel disease: the importance of twin studies. Inflamm Bowel Dis. 2011;17:1-5. https://doi.org/10.1002/ibd.21385.

10. Tysk C, Lindberg E, Järnerot G, Flodérus-Myrhed B. Ulcerative colitis and Crohn's disease in an unselected population of monozygotic and dizygotic twins. A study of heritability and the influence of smoking. Gut. 1988;29:990-996.

11. Orholm M, Munkholm P, Langholz E, Nielsen OH, Sørensen TI, Binder V. Familial occurrence of inflammatory bowel disease. N Engl J Med. 1991;324:84-88. https://doi.org/10.1056/NEJM1 99101103240203.

12. Halme L, Paavola-Sakki P, Turunen U, Lappalainen M, Farkkila M, Kontula K. Family and twin studies in inflammatory bowel disease. World J Gastroenterol. 2006;12:3668-3672. https://doi. org/10.3748/wjg.v12.i23.3668.
13. Bennett RA, Rubin PH, Present DH. Frequency of inflammatory bowel disease in offspring of couples both presenting with inflammatory bowel disease. Gastroenterology. 1991;100:16381643. https://doi.org/10.1016/0016-5085(91)90663-6.

14. Laharie D, Debeugny S, Peeters M, et al. Inflammatory bowel disease in spouses and their offspring. Gastroenterology. 2001;120:816-819. https://doi.org/10.1053/gast.2001.22574.

15. Ostrer H. A genetic profile of contemporary Jewish populations. Nat Rev Genet. 2001;2:891-898. https://doi.org/10.1038/35098506.

16. Carmi S, Hui KY, Kochav E, et al. Sequencing an Ashkenazi reference panel supports population-targeted personal genomics and illuminates Jewish and European origins. Nat Commun. 2014;5:4835. https://doi.org/10.1038/ncomms5835.

17. Zlotogora J, Patrinos GP, Meiner V. Ashkenazi Jewish genomic variants: integrating data from the Israeli National Genetic Database and gnomAD. Genet Med. 2017. https://doi.org/10.1038/ gim.2017.193.

18. Ostrer H, Skorecki K. The population genetics of the Jewish people. Hum Genet. 2013;132:119-127. https://doi.org/10.1007/ s00439-012-1235-6.

19. Weiner HA, Lewis CM. Some notes on the epidemiology of nonspecific ulcerative colitis. An apparent increase in incidence in Jews. Am J Dig Dis. 1960;5:406-418.

20. Monk M, Mendeloff AI, Siegel CI, Lilienfeld A. An epidemiological study of ulcerative colitis and regional enteritis among adults in Baltimore. I. Hospital incidence and prevalence, 1960 to 1963. Gastroenterology. 1960;1968:822-824.

21. Fahrländer $\mathrm{H}$, Baerlocher C. Clinical features and epidemiological data on Crohn's disease in the Basle area. Scand J Gastroenterol. 1971;6:657-662.

22. Brahme F, Lindström C, Wenckert A. Crohn's disease in a defined population. An epidemiological study of incidence, prevalence, mortality, and secular trends in the city of Malmö, Sweden. Gastroenterology. 1975;69:342-351.

23. Keighley A, Miller DS, Hughes AO, Langman MJ. The demographic and social characteristics of patients with Crohn's disease in the Nottingham area. Scand J Gastroenterol. 1976;11:293-296.

24. Hellers G. Crohn's disease in Stockholm county 1955-1974. A study of epidemiology, results of surgical treatment and long-term prognosis. Acta Chir Scand Suppl. 1979;490:1-84.

25. Mayberry JF, Judd D, Smart H, Rhodes J, Calcraft B, Morris JS. Crohn's disease in jewish people-an epidemiological study in south-east wales. Digestion. 1986;35:237-240. https://doi. org/10.1159/000199374.

26. Yang H, McElree C, Roth MP, Shanahan F, Targan SR, Rotter JI. Familial empirical risks for inflammatory bowel disease: differences between Jews and non-Jews. Gut. 1993;34:517-524.

27. Bernstein CN, Rawsthorne P, Cheang M, et al. A populationbased case control study of potential risk factors for IBD. Am J Gastroenterol. 2006;101:993-1002. https://doi.org/10.111 1/j.1572-0241.2006.00381.x.

28. Roth MP, Petersen GM, McElree C, Vadheim CM, Panish JF, Rotter JI. Familial empiric risk estimates of inflammatory bowel disease in Ashkenazi Jews. Gastroenterology. 1989;96:1016-1020.

29. Graham D, Boyd J, Vulkan D. 2011 Census Results England and Wales: Initial Insights About the UK Jewish Population. London: Institute for Jewish Policy Research; 2012. http://archive.jpr.org. uk/object-uk9.

30. Graham D. Jewish Couples: Marriage, Intermarriage, Cohabitation and Divorce in Britain. London: Institute for Jewish Policy Research; 2016. http://archive.jpr.org.uk/object-uk401.

31. Schiff ER, Frampton M, Ben-Yosef N, et al. Rare coding variant analysis in a large cohort of Ashkenazi Jewish families with inflammatory bowel disease. Human Genetics. 2018. https://doi. org/10.1007/s00439-018-1927-7. 
32. Frisch M, Olsen J, Andersen PK. Follow-up time bias and Crohn's disease. Lancet (London, England). 1996;347:1551. (author reply 1551-2).

33. Picco MF, Goodman S, Reed J, Bayless TM. Methodologic pitfalls in the determination of genetic anticipation: the case of Crohn disease. Ann Intern Med. 2001;134:1124-1129.

34. Borren NZ, Conway G, Garber JJ, et al. Differences in clinical course, genetics, and the microbiome between familial and sporadic inflammatory bowel diseases. J Crohn's Colitis. 2017. https ://doi.org/10.1093/ecco-jcc/jjx154.

35. Hemminki K, Li X, Sundquist K, Sundquist J. Familial association of inflammatory bowel diseases with other autoimmune and related diseases. Am J Gastroenterol. 2010;105:139-147. https:// doi.org/10.1038/ajg.2009.496.

36. Moller FT, Andersen V, Wohlfahrt J, Jess T. Familial risk of inflammatory bowel disease: a population-based cohort study 1977-2011. Am J Gastroenterol. 2015. https://doi.org/10.1038/ ajg.2015.50.

37. Zlotogora J, Zimmerman J, Rachmilewitz D. Prevalence of inflammatory bowel disease in family members of Jewish Crohn's disease patients in Israel. Dig Dis Sci. 1991;36:471-475.

38. Zhou Z, Lin X-Y, Akolkar PN, et al. Variation at NOD2/CARD15 in familial and sporadic cases of Crohn's disease in the Ashkenazi Jewish population. Am J Gastroenterol. 2002;97:3095-3101. https ://doi.org/10.1111/j.1572-0241.2002.07105.x.

39. Ben-Horin S, Avidan B, Yanai H, Lang A, Chowers Y, BarMeir S. Familial clustering of Crohn's disease in Israel: prevalence and association with disease severity. Inflamm Bowel Dis. 2009;15:171-175. https://doi.org/10.1002/ibd.20740.

40. Ben-Horin S, Tamir S, Kopylov U, et al. Familial ulcerative colitis in Israeli Jews: its prevalence and clinical severity compared to sporadic disease. Ann Gastroenterol Q Publ Hell Soc Gastroenterol. 2011;24:285-289.

41. Bijanzadeh $\mathbf{M}$. The recurrence risk of genetic complex diseases. J Res Med Sci. 2017;22:32. https://doi.org/10.4103/17351995.202143.

42. Satsangi J, Rosenberg WMC, Jewell DP. The prevalence of inflammatory bowel disease in relatives of patients with Crohn's disease. Eur J Gastroenterol Hepatol. 1994;6:413-416.

43. Monsén U, Bernell O, Johansson C, Hellers G. Prevalence of inflammatory bowel disease among relatives of patients with Crohn's disease. Scand J Gastroenterol. 1991;26:302-306.

44. Peeters M, Nevens H, Baert F, et al. Familial aggregation in Crohn's disease: increased age-adjusted risk and concordance in clinical characteristics. Gastroenterology. 1996;111:597-603.

45. Hwang SW, Kwak MS, Kim WS, et al. Influence of a positive family history on the clinical course of inflammatory bowel disease.
J Crohn's Colitis. 2016;10:1024-1032. https://doi.org/10.1093/ ecco-jcc/jjw063.

46. Ballester MP, Martí D, Tosca J, et al. Disease severity and treatment requirements in familial inflammatory bowel disease. Int J Colorectal Dis. 2017;32:1197-1205. https://doi.org/10.1007/ s00384-017-2791-y.

47. Polito JM, Childs B, Mellits ED, Tokayer AZ, Harris ML, Bayless TM. Crohn's disease: influence of age at diagnosis on site and clinical type of disease. Gastroenterology. 1996;111:580-586.

48. Grandbastien B, Peeters M, Franchimont D, et al. Anticipation in familial Crohn's disease. Gut. 1998;42:170-174.

49. Bayless TM, Picco MF, LaBuda MC. Genetic Anticipation in Crohn's Disease. Am J Gastroenterol. 1998;93:2322-2325. https ://doi.org/10.1111/j.1572-0241.1998.02322.x.

50. Faybush EM, Blanchard JF, Rawsthorne P, Bernstein CN. Generational differences in the age at diagnosis with IBD: genetic anticipation, bias, or temporal effects. Am J Gastroenterol. 2002;97:636-640. https://doi.org/10.111 1/j.1572-0241.2002.05542.x.

51. Lee JC, Bridger S, McGregor C, Macpherson AJ, Jones JE. Why children with inflammatory bowel disease are diagnosed at a younger age than their affected parent. Gut. 1999;44:808-811.

52. Kelstrup AM, Juillerat P, Korzenik J. The accuracy of selfreported medical history: a preliminary analysis of the promise of internet-based research in inflammatory bowel diseases. $J$ Crohns Colitis. 2014;8:349-356. https://doi.org/10.1016/j.crohn s.2013.09.012.

53. Randell RL, Long MD, Cook SF, et al. Validation of an internetbased cohort of inflammatory bowel disease (CCFA partners). Inflamm Bowel Dis. 2014;20:541-544. https://doi.org/10.1097/01. MIB.0000441348.32570.34.

54. Fiederling J, Shams AZ, Haug U. Validity of self-reported family history of cancer: a systematic literature review on selected cancers. Int J Cancer. 2016;139:1449-1460. https://doi.org/10.1002/ ijc.30203.

55. Qureshi N, Wilson B, Santaguida P, et al. Collection and use of cancer family history in primary care. Evid Rep Technol Assess (Full Rep). 2007;159:1-84.

56. Rivas MA, Avila BE, Koskela J, et al. Insights into the genetic epidemiology of Crohn's and rare diseases in the Ashkenazi Jewish population. PLoS Genet. 2018;14(5):e1007329. https://doi. org/10.1371/journal.pgen.1007329.

57. Levine AP, Pontikos N, Schiff ER, et al. Genetic complexity of Crohn's disease in two large Ashkenazi Jewish families. Gastroenterology. 2016. https://doi.org/10.1053/j.gastro.2016.06.040.

\section{Affiliations}

\section{Elena R. Schiff ${ }^{1}$ - Matthew Frampton ${ }^{1}$ - Francesca Semplici ${ }^{1}$ - Stuart L. Bloom ${ }^{2}$ - Sara A. McCartney ${ }^{2} \cdot$ Roser Vega $^{2}$. Laurence B. Lovat ${ }^{2,3}$. Eleanor Wood ${ }^{4}$. Ailsa L. Hartt ${ }^{5}$ Daniel Crespi ${ }^{6} \cdot$ Mark A. Furman $^{6} \cdot$ Steven Mann ${ }^{7}$. Charles D. Murray ${ }^{8} \cdot$ Anthony W. Segal $^{1} \cdot$ Adam P. Levine $^{1}$}

\author{
Matthew Frampton \\ m.frampton@ucl.ac.uk \\ Francesca Semplici \\ f.semplici@ucl.ac.uk \\ Stuart L. Bloom \\ stuart.bloom@uclh.nhs.uk \\ Sara A. McCartney \\ sara.mccartney@uclh.nhs.uk
}

Roser Vega

Roser.Vega@uclh.nhs.uk

Laurence B. Lovat

1.lovat@ucl.ac.uk

Eleanor Wood

Eleanor.Wood@homerton.nhs.uk

Ailsa L. Hart

ailsa.hart@nhs.net 
Daniel Crespi

daniel.crespi@nhs.net

Mark A. Furman

mark.furman@nhs.net

Steven Mann

steve.mann@nhs.net

Charles D. Murray

charlesmurray1@nhs.net

Anthony W. Segal

t.segal@ucl.ac.uk

Adam P. Levine

a.levine@ucl.ac.uk

1 Centre for Molecular Medicine, Division of Medicine,

University College London, London, UK

2 Department of Gastroenterology, University College London Hospital, London, UK
3 Research Department of Tissue and Energy, Division of Surgery and Interventional Science, University College London, London, UK

4 Gastroenterology Department, Homerton University Hospital, London, UK

5 Gastroenterology Department, St Mark's Hospital, London, UK

6 Centre for Paediatric Gastroenterology, Royal Free Hospital, London, UK

7 Gastroenterology Department, Barnet General Hospital, London, UK

8 Centre for Gastroenterology, Royal Free Hospital, London, UK 